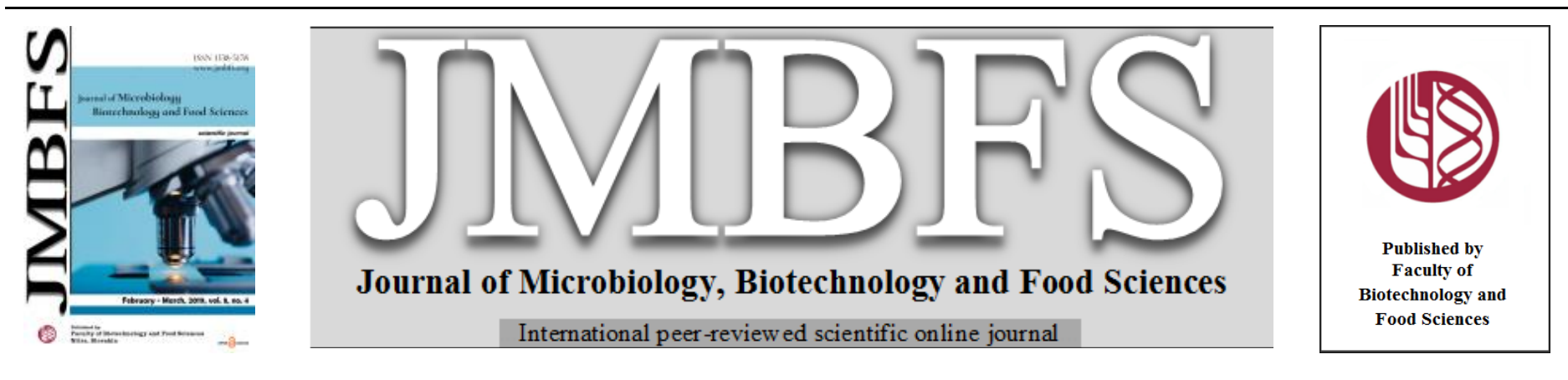

\title{
INFLUENCE OF NEW POLYPHENOL COMPOUND FROM EUPHORBIA PLANT ON MITOCHONDRIAL FUNCTION
}

Ulugbek G. Gayibov*, Esohon J. Komilov, Rakhmatilla N. Rakhimov, Nurali A. Ergashev, Nodira G. Abdullajanova, Muzaffar I. Asrorov, Takhir F. Aripov

$\operatorname{Address}(e s):$

Institute of Bioorganic chemistry named after acad. A.S. Sadykov, Academy of Sciense of Uzbekistan, 83, Mirzo Ulugbek street, 100125, Tashkent, Uzbekistan.

*Corresponding author: gayibov.ulugbek@gmail.com

doi: 10.15414/jmbfs.2019.8.4.1021-1025

ARTICLE INFO

Received 30. 3. 2018

Revised 5. 11. 2018

Accepted 7. 11. 2018

Published 1. 2. 2019

Regular article

open $\mathcal{O}$ access

\section{ABSTRACT}

In this article we investigate influence of new polyphenol compound 1-O-galloyl-6-O-bisgalloyl-2,4-valenoyl- $\beta$-D-glucose, extracted from Euphorbia Himufuza (Wild.) plant, on functional parameters of mitochondria. It was shown that above mentioned new polyphenol compound has a positive effect to some functional parameters of mitochondria. For example, this compound inhibits the mitochondrial permeability transition pore (mPTP) opening, activates ATP-dependant potassium channel and has high antioxidant/antiradical activity. Improving of functional characteristics of mitochondria by polyphenol compounds, served as the basis for the hypothesis of a possible antihypoxic effect of 1-O-galloyl-6-O-bisgalloyl-2,4-valenoyl- $\beta$-D-glucose due to its low toxicity.

Keywords: mitochondria, mPTP, mitoKATP, antioxidant activity, polyphenol compounds, hypoxia

\section{INTRODUCTION}

The mitochondria are main units integrating signals that activate different ways of programmed cell death: apoptosis, autophagy, and necrosis like programmed cell death (Sudakov et al., 2007; Bras et al., 2005; Carlotta et al., 2008). It is assumed that mitochondria participate in a «choice» of cell death way (Sudakov et al., 2007). The integration of different mechanisms of cell death predetermines the possibility of mitochondria usage as one of the main objects of cell protection from different death stimula (Asrarov et al., 2015; Gayibov et al., 2017; Ishimov et al., 2015).

The complex interaction between nutrients, oxygen, and mitochondria embodies the fundamental evolutionary struggle of eukaryotic life to survive and flourish under continuous and periodic environmental challenges. For an organism to handle extrinsic challenges such as limited oxygen/nutrients supplies or intrinsic factors such as increased energy demands it has to precisely and quickly respond to a wide spectrum of stressors and modulators. Mitochondria play a central role in this paradigm through a sophisticated array of regulatory and signaling responses that are yet to be understood in detail. For example, mitochondria play unequivocal roles in the cellular and organismal response to limited supply of oxygen (hypoxia). In acute hypoxia mitochondria have been implicated as an early respondent by releasing reactive oxygen species (ROS) which in turn trigger a cascade of events involving the stabilization of hypoxia-inducible factor (HIF-1) (Iyer et al., 1998; Chandel et al., 2000; Chandel et al., 2007).

Considering that hypoxia is on the basis of various neurological disorders, in recent years many scientists think that the mitochondria are probable «targets» for organism adaptation to oxygen deficiency (Novikov et al., 2013).

Therefore, we suppose the adaptive mechanisms that protect mitochondria dysfunction during and after hypoxia, for instance, during hypoxic preconditioning, are effective molecular mechanism of action of compounds to correction of mitochondrial functional parameters like proper functioning of mitochondrial permeability transition pore (mPTP), mitochondrial ATPdependent potassium channel (mitoKATP) as well as antioxidant system in pathological conditions (Gayibov et al., 2017).

The effects observed with most of the plant and plant-based products have been attributed to a wide variety of properties of one or more active compounds present in ethnopharmacologically important medicinal herbs (Abdramanov et al., 2017). That's why natural compounds are an inexhaustible source of medicines of various therapeutic effects. The study of the molecular mechanisms of the pathogenesis of a huge number of diseases of plants, animals and humans has shown that all of them are, in one way or another, connected with the activation or suppression of free radical processes (Goroshko et al., 2016). Therefore, it remains relevant to search and study regulators of such processes on the basis of natural and synthetic raw materials. In this regard, phenolic compounds of plant origin and their synthetic analogues are of particular interest, since they have long established themselves as powerful antioxidants/antihypoxants (Gayibov et al., 2017), anti-inflammatory (Gayibov et al, 2017), antiviral (Justyna et al., 2014) and membrane-active (Anjoo et al., 2012) agents and many other effects.

In view of the foregoing, research on the mechanisms of the action of plant compounds on the body at the molecular, membrane and cellular levels is currently relevant for the detection of potential pharmacological agents (Giorgi $\boldsymbol{e t}$ al., 2008; Salakhutdinov, 2010; Rustamova et al., 2005). In the manifestation of the physiological effects of polyphenols on the cell, their ability to change the permeability of mitochondrial membranes for various ions can play an important role.

Analyzing our data the preference is given to the polyphenol compound studied above, due to its lower toxicity and ability to dissolve in water.

The antihypoxant activity of the compounds is to a certain extent determined by their effect on the structure of mitochondrial membranes, processes of free radical oxidation and on the process of oxidative phosphorylation.

Discovered earlier by (Asrarov et al., 2015; Novikov et al., 2013), the tendency to improve the effect of polyphenolic compounds on certain functional characteristics of mitochondria, served as the basis for the hypothesis of a possible antihypoxic effect of 1-O-galloyl-6-O-bisgalloyl-2,4-valenoyl- $\beta$-D glucose (PC-3)

This work focuses on the study of influence of new polyphenol compound 1-O galloyl-6-O-bisgalloyl-2,4-valenoyl- $\beta$-D-glucose (PC-3) (Figure 1) extracted from E.Himufuza (Wild) plant, on proton transportation across mitochondrial membranes, its effect on $\mathrm{Ca}^{2+}$-dependent mitochondrial permeability transition pore in vitro as well as mitoKATP and antioxidant activity.

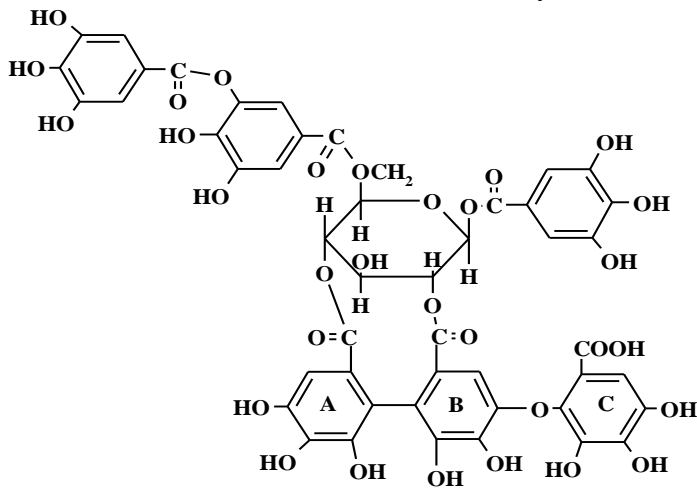

Figure 1 The chemical structure of 1-O-galloyl-6-O-bisgalloyl-2,4-valenoyl- $\beta$-Dglucose E. Himufusa (Wild) 


\section{MATERIALS AND METHODS}

\section{Isolation of mitochondria}

Mitochondria were isolated from the livers of white rats, weighed 180-200 g, by conventional differential centrifugation as described by (Schneider, Hageboom, 1951). Briefly rat liver was homogenized in a medium (1): $250 \mathrm{mM}$ sucrose, 0.5 $\mathrm{mM}$ EDTA, $10 \mathrm{mM}$ Tris-HCl buffer ( $\mathrm{pH} 7.4$ ), centrifugated at $1500 \mathrm{~g}$ for $7 \mathrm{~min}$ $\left(-2 \ldots-4{ }^{\circ} \mathrm{C}\right)$. Mitochondria were sedimented by centrifugation of supernatant at $6000 \mathrm{~g}$ for $15 \mathrm{~min}\left(-2 \ldots-4{ }^{\circ} \mathrm{C}\right)$, suspended in a small volume of the medium (1) without EDTA and stored on ice until use. The mitochondrial protein content was determined by the Lowry method in the Peterson modification (Peterson, 1977). The experiments were carried out at room temperature in the standard incubation medium required for each experiment using photocalorimeter KFK - 2 (Granat, Russia, 1991) (if not mentioned another).

\section{Measurement of passive transport for cations trough mitochondrial membranes}

The passive transport of internal mitochondrial membranes for mono- and divalent cations was studied from the change of the optical density of the mitochondrial suspension at $520 \mathrm{~nm}$ (Brierley et al., 1974). All the experiments were carried out in isoosmotic mediums containing nitrates of mono- and divalent cations, $10 \mathrm{mM}$ Tris- $\mathrm{NO}_{3},(\mathrm{pH}$ 7.4). Thus for proton permeability measurements the medium also contained $0,13 \mathrm{M} \mathrm{NH}_{4} \mathrm{NO}_{3}$, for potassium permeability measurements - $0,13 \mathrm{M} \mathrm{K} \mathrm{NO}_{3}$, sodium permeability - $0,13 \mathrm{M} \mathrm{Na}$ $\mathrm{NO}_{3}$, calcium - 0,086 $\mathrm{M} \mathrm{Ca}\left(\mathrm{NO}_{3}\right)_{2}$, magnesium - 0,086 $\mathrm{M} \mathrm{Mg}\left(\mathrm{NO}_{3}\right)_{2}$. Nonspecific mitochondria membrane permeability was measured in the medium contained 0,26 M sucrose and 1,5 мМ трис- $\mathrm{NO}_{3}$.

\section{Measurement of the mitochondrial membrane permeability through mPTP}

The state of the mitochondrial megapore, i.e. $\mathrm{Ca}^{2+}$-dependent mitochondria swelling was recorded from the change in light scattering of a mitochondria suspension (0.3-0.4 mg protein / $\mathrm{ml}$ ) at $540 \mathrm{~nm}$. Mitochondrial swelling was monitored by absorbance at $540 \mathrm{~nm}$ in presence of PC-3 (1 - $100 \mathrm{micromol})$ in incubation buffer contained $200 \mathrm{mM}$ sucrose, $20 \mu \mathrm{M}$ EGTA, $5 \mathrm{mM}$ succinate, 2 $\mu \mathrm{M}$ rotenone, $1 \mu \mathrm{g} / \mathrm{ml}$ oligomycin, $20 \mathrm{mM}$ Tris, $20 \mathrm{mM}$ HEPES, and $1 \mathrm{mM}$ $\mathrm{KH}_{2} \mathrm{PO}_{4}$, pH 7.2 (He, Lemasters, 2003). $10 \mathrm{mM} \mathrm{Ca}^{2+}$ addition was used as a control.

\section{Measurement of activation of ATP-dependent potassium channel}

The ATP-dependent potassium channel activity of the mitochondria (mito KATP channel) was monitored by dropping the optical density at a wavelength of 540 $\mathrm{nm}$ and the mitochondria were introduced into the incubation medium of the following composition (in $\mathrm{mM}$ ): $\mathrm{KCl}-125$, Hepes-10, succinate-5, $\mathrm{MgCl}_{2}-1$, $\mathrm{K}_{2} \mathrm{HPO}_{4}-2.5, \mathrm{KH}_{2} \mathrm{PO}_{4}-2.5$, rotenone-0.005 and oligomycin-0.001 (Vadzyuk, Kosterin, 2008). Then PC-3 was added at concentrations $1-50$ micromol. 10 $\mathrm{mM}$ ATP was used as a control.

\section{Lipid peroxidation as measured by $\mathrm{Fe}^{2+} /$ ascorbate}

Lipid peroxidation (LPO) was recorded by inhibition of $\mathrm{Fe}^{2+} /$ ascorbate-dependent liver mitochondrial swelling by photometric method in incubation medium contained: $\mathrm{KCl}-125 \mathrm{mM}$, Tris-HCl-10 mM, pH 7.4, the final amount of protein in the incubation medium was $0.5 \mathrm{mg} / \mathrm{ml}$ (Schneider et al., 1948). $\mathrm{FeSO}_{4}-10 \mu \mathrm{M}$ and ascorbate- $600 \mu \mathrm{M}$ were added to induce mitochondria swelling. Al experiments were conducted at $24-26^{\circ} \mathrm{C}$ so that the integrity of the mitochondria was maintained during incubation.

\section{DPPH kinetic analysis}

Fitting of the experimental data was carried out by using the LevenbergMarquardt method (Marquardt, 1963). Recording of spectrophotometric data was taken until the disappearance of DPPH in the presence of PC-3 To follow the kinetic behavior of DPPH radical scavenging activity certain amount of PC-3 was added to $3 \mathrm{ml}$ of DPPH ethanol solution $(0.1 \mathrm{mM})$ to get the final concentration of studied polyphenol 10 micromol and the absorbance was measured using SF46 (LOMO, Russia, 1996) after each 15 s until it becomes constant.

\section{Drugs and chemicals}

These given chemical reagents were used: EGTA, EDTA, cyclosporine A ("Sandoz", Switzerland), rotenone, tris-HCl (Serva, Germany), Sucrose (Russia), DPPH (Sigma, USA), $\mathrm{CaCl}_{2}$ ("Sigma", USA). Other reagents were chemically pure and received from local companies. PC-3 was provided by Prof. Mavlyanov S.M.

\section{Data analysis}

Statistical analyses were performed using the statistical package Origin 6 (OriginLab Corporation, USA). The data was evaluated using parametric Student's t-test, we expressed as $\mathrm{M} \pm \mathrm{m}$. Deemed authentic results are expressed at $*$ - $\mathrm{P}<0.05 ; * *-\mathrm{P}<0.01 ; * * *-\mathrm{P}<0.001$.

\section{RESULTS AND DISCUSSION}

\section{Passive transport}

When studying the effect of polyphenol compound on the passive permeability of rat liver mitochondrial membranes, it was shown that polyphenol compound at concentrations ranging $10-50 \mu \mathrm{M}$ increased passive permeability for monovalent cations such as $\mathrm{H}^{+}, \mathrm{K}^{+}$and $\mathrm{Na}^{+}$. Increasing of the concentration of polyphenol compound led to a further increasing of passive permeability of mitochondrial membranes for monovalent cations, e.g. the process had concentration-dependent manner. Moreover, the proton permeability of mitochondrial membranes was higher than the permeability of membranes to other monovalent cations in the presence of the studied compound. In general, the change in permeability of the inner mitochondrial membrane can be represented by the following relationship induced by polyphenolic compound in a relatively high dose $(50 \mu \mathrm{M})$ :

$$
H^{+}: K^{+}: N a^{+}=1,00: 0,74: 0,52
$$

In these calculations, the increasing of the permeability of $\mathrm{H}^{+}$through mitochondrial membrane was taken as 1 .

The effect of the studied compound on the permeability of mitochondrial membranes could be explained by two mechanisms. First, polyphenol can penetrate by simple diffusion into the interior of the mitochondria, binding the cations with its hydroxyl or carboxyl groups. Secondly, the polyphenol molecule can be embedded in the mitochondrial membranes and form pores that carry the corresponding cations. Under these conditions, the polyphenol does not affect the passive transport of divalent cations $\left(\mathrm{Ca}^{2+}, \mathrm{Mg}^{2+}\right)$ through the mitochondrial membranes.

\section{Influence of 1-O-galloyl-6-O-bisgalloyl-2,4-valenoyl- $\beta$-D-glucose (PC-3) to mPTP}

One of the important functional parameters of the cell is functional activity of mitochondrial permeability transition pore (mPTP). The mPTP play an important event in necrosis and apoptosis in hepatocytes after oxidative stress, $\mathrm{Ca}^{2+}$ toxicity, and ischemia/reperfusion (Kim et al., 2013). The core components of the mPTP are the adenine nucleotide translocase (ANT) and a mitochondrial cyclophilin D (CyP-D) that exhibit peptidyl-prolyl cis-trans isomerase (PPIase) activity. Triggered by $\mathrm{Ca}^{2+}$, which binding to the ANT is inhibited by adenine nucleotides, this PPIase activity causes a conformational change of the carrier that converts it into a nonspecific pore (Halestrap et al., 2004). In normal physiological conditions mPTP transports ATP to cytosol and ADP from cytosol to mitochondria through mitochondrial membrane (Halestrap et al., 2004)

It was shown that inhibitors of the MPTP have been shown to reduce cardiac ischemia-reperfusion injury (Martel et al., 2012). Furthermore, most cardioprotective agents appear to reduce ischemic cell death either by reducing the triggers for the opening of the mPTP, such as reducing $\mathrm{Ca}^{2+}$ overload or reactive oxygen species, or by direct inhibition of the $\mathrm{MPTP}$.

Mitochondria are the key targets of ROS, which are thought to regulate mitochondrial dysfunction and the promotion of apoptosis. Elevated ROS production causes mitochondrial damage, such as collapse of the mitochondrial membrane potential, which is one of the reasons of opening the mitochondrial permeability transition pores, leading to the release of pro apoptotic proteins into the cytoplasm (Balaban et al., 2005; Choi, 2012).

Mitochondrial permeability transition pore, also known as megachannel or multiple conductance channel, is multiprotein complex formed at the contact site between the inner and outer mitochondrial membranes, which helps regulate matrix $\mathrm{Ca}^{2+}$ concentrations, $\mathrm{pH}, \Delta \psi \mathrm{m}$ and mitochondrial volume. Under normal physiological conditions, the mitochondrial inner membrane is impermeable to all, but a few, selected metabolites and ions (Halestrap et al., 2004). The open channel has a diameter of 1.0-1.3 nm and allows passage of solutes with molecular masses up to $1.5 \mathrm{kDa}$ (Crompton, 1999). Opening of the $\mathrm{mPTP}$ is tightly regulated by $\Delta \psi \mathrm{m}$ and matrix $\mathrm{pH}$, and can be specifically inhibited by cyclosporine A, bongkrekkic acid, EDTA or magnesium (Kroemer, Reed, 2000).

Adding mPTP-inductor $\left(\mathrm{Ca}^{2+}\right.$ ions $)$ into the incubation medium at a concentration of $10 \mu \mathrm{M}$ causes mitochondrial swelling (Figure 2, control), that indicates the open state of mPTP. Cyclosporin A (CsA), a specific inhibitor of mPTP, prevents swelling of the mitochondria under the above conditions (Figure 2, CsA), i.e. mPTP remains in the closed state even in the presence of $\mathrm{Ca}^{2+}$ ions. Experimental data show that 1,4,6 tri-O-galloyl-2,3-valonoyl- $\beta$-D-glucose at a concentration of $10 \mu \mathrm{M}$ and in the presence of $\mathrm{Ca}^{2+}$ ions inhibits the mPTP opening to $12.6 \%$, and 
in concentration of $80 \mu \mathrm{M}$ suppresses its opening to $89.7 \%$ compared to the control. The results show that PC-3 inhibits the opening of mPTP in rat liver depending on the concentration. It has been shown that PC-3 increases passive permeability for monovalent cations. One would assume that induction of passive membrane permeability under the action of PC-3 causes swelling of the organelles, a drop in the membrane potential of $\psi$ and the opening of mPTP. However, the results obtained by us do not correspond to this assumption. According to our results, PC-3 simultaneously increasing passive permeability (Asrarov et al., 2015), has an inhibitory effect on mPTP. This may be due to the antioxidant properties of PC-3 (Asrarov et al., 2015), which has a stabilizing effect on the membrane.

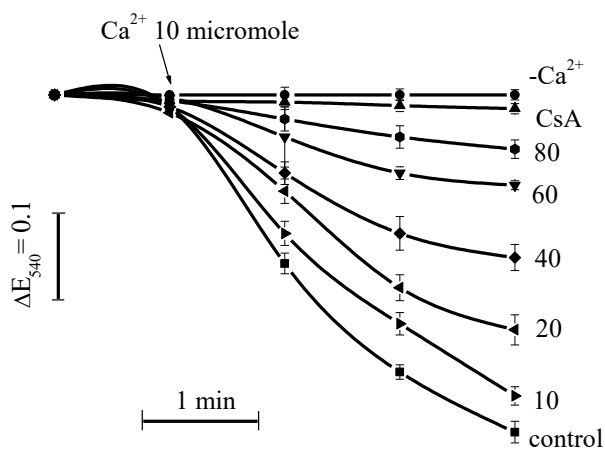

concentration of compound, micromole

Figure 2 Influence of 1-O-galloyl-6-O-bisgalloyl-2,4-valenoyl- $\beta$-D-glucose (PC3 ) on mitochondrial swelling. Incubation medium is $(\mathrm{mM})$ : sucrose, 20 $\mu \mathrm{M}$ EGTA, $5 \mathrm{mM}$ succinate, $2 \mu \mathrm{M}$ rotenone, $1 \mu \mathrm{g} / \mathrm{ml}$ oligomycin, $20 \mathrm{mM}$ Tris, $20 \mathrm{mM}$ HEPES, and $1 \mathrm{mM} \mathrm{KH} \mathrm{KH}_{4}, \mathrm{pH} 7.2$, mitochondrial proteins $0,3-0,4$ $\mathrm{mg} / \mathrm{ml} ;(\mathrm{n}=3-5)$

Experiments on mPTP showed that 1-O-galloyl-6-O-bisgalloyl-2,4-valenoyl- $\beta$-D glucose in dose-dependent manner can inhibit pore opening. Mitochondrial membrane is slightly permeable to some anions and cations, like $\mathrm{NH}_{4}{ }^{+}$, but not permeable to chloride, sulphate, as well as to protons. Penetration of $\mathrm{NH}_{4}{ }^{+}$does not cause mitochondria swelling as $\mathrm{H}^{+}$or $\mathrm{OH}^{-}$are transported outside the cell thus protecting mitochondria from increased osmotic pressure. When both cation and anions penetrate into mitochondria the swelling process increases as increases osmotic pressure. $\mathrm{NH}_{4}{ }^{+}$penetrates as neutral molecule of ammonia. We propose that in presence of $\mathrm{PC}-3$ cations and anions penetrate into mitochondria causing significant mitochondria swelling.

There are 4 main causes of inhibition of mPTP: increasing of $\mathrm{Ca}^{2+}$ concentration, low $\mathrm{pH}$, membrane potential and influence directly to $\mathrm{mPTP}$ proteins. Considering that flavonoids are able to chelate $\mathrm{Fe}^{2+}, \mathrm{Fe}^{3+}, \mathrm{Cu}^{2+}, \mathrm{Zn}^{2+}, \mathrm{Al}^{3+}$ and $\mathrm{Mg}^{2+}$ cations, but are unable to bind $\mathrm{Na}^{+}, \mathrm{K}^{+}$and $\mathrm{Ca}^{2+}$ [33] there is no decrease in calcium ions, which could lead to inhibition of mPTP. However, it is well known that polyphenol compounds are weak acids. One of the supposing of inhibition of mPTP may be connected with decreasing of medium $\mathrm{pH}$ with the help of polyphenol compounds. Another supposing is decreasing of membrane potential which causes by AOA of studied compound.

\section{Activation of mitoKATP by 1-O-galloyl-6-O-bisgalloyl-2,4-valenoyl-p-D- glucose (PC-3)}

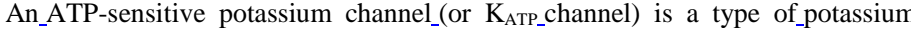
channel that is gated by intracellular_nucleotides, ATP_and_ADP. ATP-sensitive potassium channels are composed of $\mathrm{K}_{\mathrm{ir}} 6$.x-type subunits, which is a majo component of the ATP-sensitive $\mathrm{K}^{+}$channel, and_sulfonylurea receptor_(SUR) subunits, along with additional components (Stephan et al., 2006). Many scientists suppose that mitoKATP, especially its activation, play an importan role in ischemic diseases (Shi et al., 2012; Li et al., 2010; Miura et al., 2003; Raveaud et al., 2009) and have been reported to possess protective role agains various cardiovascular complications. Several experimental studies have shown a wide range of possible clinical uses of receptor for KATP channel openers (KCOs) as bronchodilators, vasodilators and bladder relaxants. In addition, $\mathrm{KCO}$ show various cardioprotective effects against arrhythmias, angina and heart failure (Rohilla et al., 2012). However The mechanism of cardioprotection by mitoKATP is poorly understood (Garlid, 2000).

Figure 3 shows the data of experiments using PC-3 as the activator of the mitoKATP channel.

The results show that PC-3, at the concentrations 10 and $20 \mu \mathrm{M}$, activates the mitoKATP channel (Figure 3). And at concentration $80 \mu \mathrm{M}$ and above there is an output on the board. Considering that the action of PC-3 on the activity of the mitoKATP channel is dose-dependent, it should be specially noted that this action of PC-3 per mito KATP channel has the form of a saturation graph.

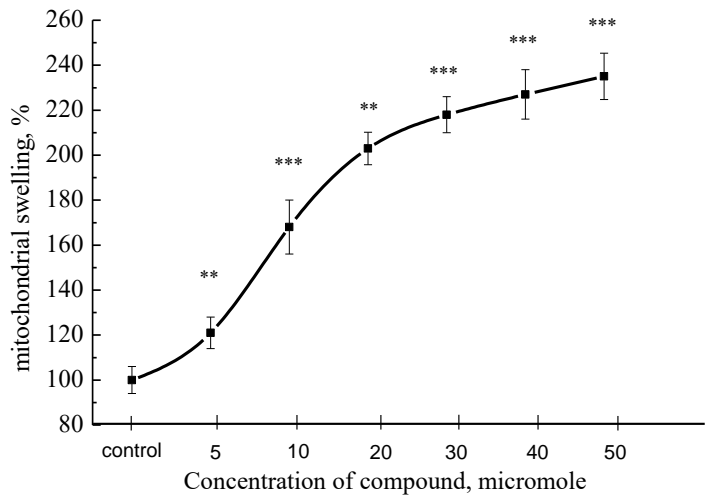

Figure 3 Influence of 1-O-galloyl-6-O-bisgalloyl-2,4-valenoyl- $\beta$-D-glucose (PC3 ) on the activation of mitoKATP channel. Incubation medium is $(\mathrm{mM}): \mathrm{KCl}$ 125 , Hepes-10, succinate-5, $\mathrm{MgCl}_{2}-1, \mathrm{~K}_{2} \mathrm{HPO}_{4}-2.5, \mathrm{KH}_{2} \mathrm{PO}_{4}-2.5$, rotenone- 0.005 and oligomycin-0.001. $\mathrm{pH} 7,4$. (** $\left.-\mathrm{P}<0,01,{ }^{* * *}-\mathrm{P}<0,001 ; \mathrm{n}=4\right)$

Antioxidant and antiradical activities of 1-O-galloyl-6-O-bisgalloyl-2,4valenoyl-p-D-glucose (PC-3)

The effect of various concentrations of PC-3 on the process of LPO mitochondrial membranes induced by the $\mathrm{Fe}^{2+} /$ ascorbate system in vitro experiments was studied. Inclusion of the $\mathrm{Fe}^{2+} /$ ascorbate system into the incubation medium induces LPO, resulting in violation of barrier function of the mitochondrial membranes, and the organelles swelling sharply compared to the control (Figure 4). Under the induction of lipid peroxidation, introduction of PC3 at a concentration of $2 \mu \mathrm{M}$ into the incubation medium inhibits mitochondrial swelling, that is indicative for antioxidant properties of studied compound. The effect of PC-3 on LPO in mitochondrial membranes depended on its concentration, i.e. with its increase in the incubation medium, the percentage of inhibition became more pronounced. Complete inhibition of liver mitochondrial swelling, i.e. of the LPO process was noted at a concentration of $10 \mu \mathrm{M}$ of the test compound. At the same time, the concentration that caused the half-maxima inhibition of the LPO process $\left(\mathrm{IC}_{50}\right)$ for this polyphenolic compound was $6.08 \pm 0.06 \mu \mathrm{M}$. Thus, in experiments it was shown that PC-3 possesses high AOA

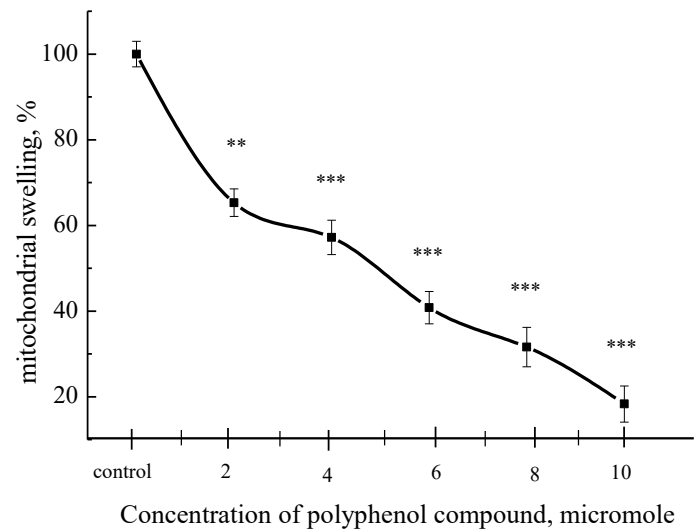

Figure 4 Influence of 1-O-galloyl-6-O-bisgalloyl-2,4-valenoyl- $\beta$-D-glucose (PC3) on the $\mathrm{Fe}^{2+}$ /ascorbate induced mitochondrial swelling. Incubation medium is $(\mathrm{mM})$ : KCl-125 mM, Tris-HCl-10 mM, pH 7.4, concentration of $\mathrm{FeSO}_{4}-10 \mu \mathrm{M}$ ascorbate- $600 \mu \mathrm{M}$, protein $0.5 \mathrm{mg} / \mathrm{ml}$

It was shown that flavonoids are located in the membrane layer between the lipid bilayer and aqueous phase and can influence both enzymatic and non-enzymatic peroxidation of lipids (Packer, 2001). It was reported that flavonoids also directly interact with biological membranes, reducing their fluidity, making them more resistant to many oxidative factors and hampering diffusion of free radicals (Terao et al., 1994; Harbome, Williams, 1992). Besides, polypheno compounds can chelate different metal ions. These factors do not allow to directly estimate the contribution of each of these effects to the overall antioxidant activity of the drugs. In this case it is useful to use compounds bearing free valence, which is stable organic radicals.

Thus, we investigate the antiradical activity (ARA) of PC-3. ARA of abovementioned compound has been studied by measuring the change in optical density of 2,2-diphenyl-1-picrylhydrozyl (DPPH) ethanol solution after adding 
compound. By analyzing kinetic curves of DPPH reduction with studying compound it has been shown that PC-3 has the high ARA.

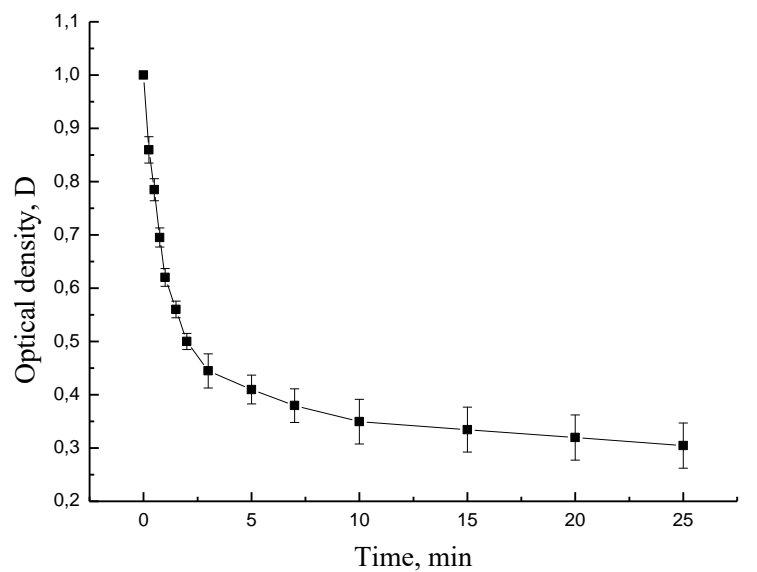

Figure 5 Kinetic curves of ARA of 1-O-galloyl-6-O-bisgalloyl-2,4-valenoyl- $\beta$ D-glucose (PC-3) in ethanol solutions of DPPH concentrations of polyphenol is 10 micromole.

Correlation coefficient between AOA and ARA of PC-3 is $\mathbf{r = 0 . 8 9}$.

\section{CONCLUSION}

The wide range of studies shows that mitochondria are an important target in the development of such human diseases as heart ischemia, neurodegenerative disorders, etc. Even though the model of the MPTP is still evolving it is already clear that MPTP, while opened, enables molecules of $<1.5 \mathrm{kDa}$ to passage freely into the mitochondria leading finally to apoptosis. Increasing level of ROS is found to be the factor causing MPTP opening. Our results show that studied polyphenol PC-3 inhibits $\mathrm{MPTP}$ by scavenging free radicals. Moreover, our present data represent that PC-3 activates mitoKATP while avoiding amplifying the ROS production. Although the roles of mitoKATP and $\mathrm{mPTP}$ are still controversial our data suggests that studied polyphenol modifies both mPTP and mitoKATP preventing from mitochondria swelling, ROS production and thus from apoptosis. Future studies will be required to demonstrate the role of PC-3 in mitochondria protection and the exact mechanisms of its activity.

Acknowledgments: Authors thank head of experimental technology laboratory of the Institute of Bioorganic chemistry Uzbek Academy of Sciences prof. S.M Mavlyanov for compound 1-O-galloyl-6-O-bisgalloyl-2,4-valenoyl- $\beta$-D-glucose (PC-3) kindly provided for the research.

\section{REFERENCES}

ABDRAMANOV, A., MASSANYI, P., SARSEMBAYEVA, N., USENBAYEV A., ALIMOV, J., TVRDA, E. 2017. The in vitro effect of elderberry (Sambucus Nigra) extract on the activity and oxidative profile of bovine spermatozoa Journal of microbiology, biotechno;ogy and food sciences, 6(6), 1319-1322. doi: 10.15414/jmbfs.2017.6.6.1319-1322

ANKUR, R., ARTI, M., SEEMA, R., ASHOK, K. 2012. Mitochondrial ATP Sensitive Potassium Channels and Cardioprotection. International Journal of Drug Development \& Research, 4(2), 92-98.

ARORA, A., BYREM, T.M., NAIR, M.G., STRASBURG, G.M. 2000 Modulation of liposomal membrane fluidity by flavonoids and isoflavonoids. Arch. Biochem. Biophys, 373, 102-109.

ASRAROV, M.I., KOMILOV, E.DJ., ERGASHEV, N.A., POZILOV M.K., ESHBAKOVA, K.A., TOSHMATOV, Z.A., TASHBEKOVA, M.X. 2015. To the mechanism of action of luteolin flavone on the function of rat liver mitochondria. Biological, medical and pharmacological chemistry questions, 12, 38-43. (in Russian language).

BALABAN, R.S., NEMOTO, S. FINKEL, T. 2005. Mitochondria, oxidants, and aging. Cell, 120, 483-495. http://dx.doi. org/10.1016/j.cell.2005.02.001

BRAS, M., QUEENAN, B., SUSIN, S. A. 2005. Programmed Cell Death via Mitochondria:Different Modes of Dying. Biochemistry (Moscow), 70(2), 231239.

BRIERLEY, G.P. 1974. Passive permeability and energy-linked ion movements in isolated heart mitochondria. Ann. N. Acad. Sci. 227, 398-411.

CHANDEL, N.S., BUDINGER, G.R. 2007. The cellular basis for diverse responses to oxygen. Free Radic Biol Med, 42, 165-174.

CHANDEL, N.S., MCCLINTOCK, D.S., FELICIANO, C.E., WOOD, T.M., MELENDEZ, J.A. 2000. Reactive oxygen species generated at mitochondrial complex III stabilize hypoxia-inducible factor-1alpha during hypoxia: a mechanism of $\mathrm{O}_{2}$ sensing. J Biol Chem, 275, 25130-25138.
CHOI, E.M. 2012. Magnolol protects osteoblastic MC3T3-E1 cells agains antimycin A-induced cytotoxicity through activation of mitochondrial function. Inflammation, 35, 1204-1212. http://dx.doi.org/10.1007/s10753-012-9430-0 CROMPTON, M. 1999. The mitochondrial permeability transition pore and its role in cell death. Biochem. J. 341, 233-249.

CYBULSKIY, A.V., POPOV, A.M., ARTYUKOV, A.A., KOSTECKIY, E.YA., KRIVOSHAPKO, O.N., MAZEYKA, A.N., KOZLOVSKAYA, E.P. 2011. A comparative study of the therapeutic effect of luteolin, rosmarinic acid and echinochrome A in experimental cardiopathology induced by stress. Biomedical chemistry, 57(3), 314-325. (in Russian language).

GARLID, K.D. 2000. Opening mitochondrial KATP in the heart - what happens, and what does not happen. Basic Res Cardiol, 95, 275 - 279.

GAYIBOV, U.G., KOMILOV E.DJ., ERGASHEV, N.A., RAKHIMOV, R.N., ABDULLAJANOVA, N.G., ASRAROV, M.I., ARIPOV, T.F. 2017. Antioxidan and membrane activity of PC-1. Uzbek biological journal, 2, 19-23. . (in Russian language)

GAYIBOV, U.G., KOMILOV E.DJ., ERGASHEV, N.A., RAKHIMOV, R.N. ABDULLAJANOVA, N.G., ASRAROV, M.I., ARIPOV, T.F. 2017. Influence of poliphenol compound PC-1 of permeability of rat liver mitochondrial membrane Reports of Uzbek Academy of Sciences, 5, 17-22. (in Russian language).

GAYIBOV, U.G., KOMILOV, E.Dj., RAKHIMOV, R.N. 2017. Antihypoxan activity of polyphenol compounds from Euphorbia plants. Scientific Conference of PhD. Students of FAFR and FBFS SUA in Nitra, 25

GOROSHKO, O.A., KUKES, V.G., PROKOFIEV, A.B, ARKHIPOV, V.V., DEMCHENKOVA, E.Y. 2016. Clinico-pharmacological aspects of application of antioxidant drugs. International Journal of Applied and Fundamental Research, 4, 905-912. (in Russian language).

GIORGI, C., ROMAGNOLI, A., PINTON, P., RIZZUTO, R. 2008. $\mathrm{Ca}^{2+}$ Signaling, Mitochondria and Cell Death. CurrentMolecularMedicine, 8, 119-130 HALESTRAP, A.P., CLARKE, S.J., SABZALI, A. 2004. Javadov1 Mitochondrial permeability transition pore opening during myocardia reperfusion - a target for cardioprotection. Cardiovascular Research, 61, 372385

HARBORNE, J.B., WILLIAMS, C.A. 2000. Advances in flavonoid research since. Phytochemistry, 55, 481-504.

HE, L., LEMASTERS, J.J. 2003. Heat shock suppresses the permeability transition in rat liver mitochondria. J. Biol. Chem. 278, 16755-60 http://dx.doi.org/10.1074/jbc.M300153200

ISHIMOV, U.J., ABDULLAYEVA, G.T., ZIYAVITDINOV, J.F., ASROROV, A.M., ERGASHEV, N.A., ASRAROV, M.I. 2015. The effects of isolated fractions of red pepper Capsicum Annuиm L. on the mitochondrial permeability transition pore and lipid peroxidation, Journal Microbiology, Biotechnology and Food Sciences, 5(3), 259-262. doi: 10.15414/jmbfs.2015/16.5.3.259-262

IYER, NV., KOTCH, L.E., AGANI, F., LEUNG, S.W., LAUGHNER, E. 1998 Cellular and developmental control of $\mathrm{O}_{2}$ homeostasis by hypoxia-inducible factor 1 alpha, Genes Dev., 12, 149-162.

KAMBOJ, A., SALUJA, A.K., KUMAR, M., ATRI, P. 2012. Antiviral activity of plant polyphenols. Journal of Pharmacy Research, 5(5), 2402-2412.

KIM, J., KIM, J., MCGINTY, R.K., NGUYEN, U.T., MUIR, T.W., ALLIS, C.D 2013. The n-SET Domain of Set1 Regulates H2B Ubiquitylation-Dependen H3K4 Methylation. Molecular cell, 49(6), 1121-1133. DOI: https://doi.org/10.1016/j.molcel.2013.01.034

KROEMER, G., REED, J.C. 2000. Mitochondrial control of cell death. Nature Medicine, 6, 513-519 DOI:10.1038/74994

LI, G.R., DONG, M.Q. 2010. Pharmacology of cardiac potassium channels. Adv Pharmacol, 59, 93-134.

MARQUARDT, D., 1963. An algorithm for least-squares estimation of nonlinear parameters. J. Soc. Ind. Appl. Math. 11, 431-441.

MARTEL, C., HUYNH, L.H., GARNIER, A., VENTURA-CLAPIER, R. BRENNER, C. 2012. Inhibition of the Mitochondrial Permeability Transition for Cytoprotection: Direct versus Indirect Mechanisms. Biochemistry Research International, 2012, 1-13. doi:10.1155/2012/213403

MIERZIAK, J., KOSTYN, K., KULMA, A. 2014. Flavonoids as Important Molecules of Plant Interactions with the Environment. Molecules, 19, 16240 16265 .

MIURA, T., MIKI, T. 2003. ATP-sensitive K+ channel openers: old drugs with new clinical benefits for the heart. Curr Vasc Pharmacol, 1, 251-8.

NOVIKOV, V.E., LEVCHENKOVA, O.S. 2013. Promising directions of search for antihypoxants and targets of their action. Experimental and clinical pharmacology 76(5), 37-47. (in Russian language).

PACKER, L. 2001. Flavonoids and Other Polyphenols: Methods in Enzymology. Academic Press: San Diego, CA, USA, 335, 15-34.

PETERSON, G.L. 1977. A simplification of the protein assay method of Lowre et al. Which is more generally applicable. Analytical biochemistry. 83(2), 346 56. doi: 10.1016/0003-2697(77)90043-4.

RAVEAUD, S., VERDETTI, J., FAURY, G. 2009. Nicorandil protects ATP sensitive potassium channels against oxidation-induced dysfunction in cardiomyocytes of aging rats. Biogerontology, 10, 537-47.

RUSTAMOVA, R.P., IRGASHEVA, G.M., XUSHBAKTOVA, Z.A. KLEMESHEVA, L.S., SHIRINOVA, I.A., ALMATOV, K.T. 2005. Influence of 
some flavones on the energy metabolism of mitochondria. Short massage. Biological, medical and pharmacological chemistry questions, 4, 39-45. (in Russian language).

SALAKHUTDINOV, B.A., GAYIBOV, U.G., TILYABAEV, K.Z. 2010 Antioxidant and membrane activities of gossypol and its derivatives. Special edition. Uzbek biological journal, 83-87. (in Russian language).

SCHNEIDER, W.C., HAGEBOOM, G.H. 1951. Cutochemical studies of mammalian tissues: The isolation of cell components by differentia centrifugation. Cancer Research, 11(4), 1-56.

SCHNEIDER, W.C., HAGEBOOM, G.H., PALLADE, G.E. 1948. Cytochemical studies of mammalian tissues; isolation of intact mitochondria from rat liver; some biochemical properties of mitochondria and submicroscopic particulate material. J. Biol. Chem. 172(2), 619-35.

SHI, W., YANG, Y., SHI, Y., JIANG, C. 2012. K(ATP) channel action in vascular tone regulation: from genetics to diseases. Sheng Li Xue Bao, 64, 1-13.

STEPHAN, D., WINKLER, M., KÜHNER, P., RUSS, U., QUAST, U. 2006. Selectivity of repaglinide and glibenclamide for the pancreatic over the cardiovascular K(ATP) channels. Diabetologia. 49 (9), 203948. doi:10.1007/s00125-006-0307-3.PMID 16865362

SUDAKOV, N.P., NIKIFOROV, S.B. KONSTANTINOV, YU.M. LEPEKHOVA S.A. 2007. The role of mitochondria in realization of programmed cell death. Newsletter East Siberian Scientific Center of the Siberian Branch of the Russian Academy of Medical Sciences, 1 (53). (in Russian language).

TERAO, J., PISKULA, M., YAO, Q. 1994. Protective effect of epicatechin, epicatechin gallate, and quercetin on lipid peroxidation in phospholipid bilayers. Arch. Biochem. Biophys, 308, 278-284.

VADZYUK, O.B., KOSTERIN, S.A. 2008. Diazoxide-induced mitochondrial swelling of rat myometrium as evidence of activation of an ATP-sensitive $\mathrm{K}^{+}$channel. Biochemical journal of Ukraine, 80(5), 45-51. (in Russian language). 